\title{
GLOBAL FINANCIAL MARKETS AND THE RISK PREMIUM ON U.S. EQUITY
}

\author{
K.C. Chan \\ G. Andrew Karolyi \\ René M. Stulz
}

Working Paper No. 4074

NATIONAL BUREAU OF ECONOMIC RESEARCH 1050 Massachusetts Avenue

Cambridge, MA 02138

May 1992

This paper is part of NBER's research program in Asset Pricing. Any opinions expressed are those of the authors and not those of the National Bureau of Economic Research. 
NBER Working \#4074

May 1992

\section{GLOBAL FINANCIAL MARKETS AND THE RISK PREMIUM ON U.S. EQUITY}

\section{ABSTRACT}

We document that there is a significant foreign influence on the risk premium of U.S. assets. Using a bivariate GARCH-in-mean process for conditional expected excess returns, we find that the conditional expected excess return on U.S. stocks is positively related to the conditional covariance of the return of these stocks with the return on a foreign index but is not related to its own conditional variance. Further, we are unable to reject the international version of the CAPM. Evidence is presented for different model specifications, multiple-day returns and alternative proxies of foreign stock returns including the Nikkei 225 Stock Average, Morgan Stanley Japan and Morgan Stanley EAFE indices.

K.C. Chan

Associate Professor

Faculty of Finance

College of Business

Ohio State University

1775 College Road

Columbus, $\mathrm{OH} 43210$
G. Andrew Karolyi Assistant Professor Faculty of Finance College of Business Ohio State University 1775 College Road Columbus, $\mathrm{OH} 43210$

René M. Stulz

Riklis Chair in Business

College of Business

Ohio State University

314 Hagerty Hall

1775 College Road

Columbus, $\mathrm{OH} 43210$

and NBER 


\section{Introduction}

What drives the risk premium on U.S. equity? If the U.S. capital markets are segmented from foreign markets or if U.S. assets constitute most of the wealth traded on internationally integrated markets, the risk premium on U.S. assets should be determined in the U.S. and should not be affected by foreign capital markets. Until the mid-1970s, these conditions seemed to prevail. However, since then, capital markets have apparently become increasingly integrated internationally and the market value of U.S. assets has become a smaller fraction of world wealth. These developments suggest that the risk premium on U.S. assets may now be determined primarily on world capital markets rather than on U.S. capital markets. In this paper, we investigate this issue and find empirical evidence of a significant foreign influence on the risk premium of U.S. assets.

The capital asset pricing model implies that the risk of the market portfolio is measured by the variance of its returns and that, therefore, the risk premium for the market portfolio increases with the variance of the portfolio's returns. Further, with risk averse investors, the addition of a mean preserving spread to the distribution of the return of the market portfolio increases the risk premium, so that even if the capital asset pricing model does not hold, one would typically expect a positive relation between the risk premium and the variance of the market portfolio. Merton (1980) estimates the relation between the risk premium and volatility using contemporaneous variance estimates. French, Schwert and Stambaugh (1987) provide evidence that there is a positive relation between the conditional expected excess returns on the market portfolio and the conditional variance of its returns using a generalized autoregressive conditional heteroscedasticity (GARCH) representation developed by Engle (1982) and Bollerslev (1986). They use daily data from January 1928 to December 1984 for the excess returns on the market with Standard and Poor's S\&P 500 index proxying for the market portfolio.

For most of the sample period studied by French, Schwert and Stambaugh (1987), foreign capital markets were substantially segmented from the U.S. capital markets and their capitalization was small relative to the capitalization of U.S. markets. There is now substantial evidence that stock 
markets are reasonably well-integrated. For instance, Cho, Eun and Senbet (1986), Wheatley (1988), Korajczyk and Viallet (1989), Gultekin, Gultekin and Penati (1989), Cumby (1990), Harvey (1991), Bekaert and Hodrick (1992) and Campbell and Hamao (1992) provide evidence of integration, especially during the $1980 \mathrm{~s}$, using a variety of asset pricing models with monthly data. Further, as Figure 1 indicates, the capitalization of U.S. stocks has become a smaller part of the capitalization of the world market portfolio of common stocks. These two developments suggest that the S\&P 500 is unlikely to have been an adequate proxy for the world market portfolio over the last decade.

Using the capital asset pricing model, the evidence that stock market$s$ are fairly well integrated suggests that the risk premium on the market portfolio of U.S. assets depends on the covariance of its returns with the returns on the world market portfolio. This covariance is a weighted average of the variance of the market portfolio of U.S. assets and the covariance of the returns on the market portfolio of U.S. assets with the market portfolio of non-U.S. assets, where the weights are the proportions of U.S. and foreign stocks in the world market portfolio. Even if the capital asset pricing model does not hold, however, this covariance may be an important determinant of the risk premium on the U.S. market portfolio. For instance, in Merton's (1973) intertemporal capital asset pricing model, the risk premium on a portfolio is still an increasing function of the covariance of the returns of that portfolio with the market portfolio.

In our empirical work, we model the daily excess returns of the S\&P 500 and of a portfolio of non-U.S. assets jointly using a bivariate GARCH-inmean representation. We find that the conditional expected excess returns on the U.S. market portfolio are significantly related to the conditional covariance of the S\&P 500 with Japan's Nikkei 225 index, but not significantly to the conditional variance of the S\&P 500. We obtain a similar though weaker result if the market portfolio of foreign assets is approximated by the Morgan Stanley EAFE index (which is a value-weighted index comprising stocks from Europe, Australia and the Far East) and the Morgan Stanley Japan index. We also show that this result is robust to a number of alternative econometric specifications as well as different measurement intervals for the 
returns data. This result implies that the impact of foreign stock markets on the risk premium of the U.S. market portfolio cannot be neglected.

When we compare the restricted version of the model which corresponds to the international version of the CAPM, we find that we cannot reject the model at the 0.05 significance level. However, given the small number of sasets used in our tests, one might argue that this significance level is too low. At the 0.10 level, the model is rejected when the Nikkei indices are used, but not otherwise. Further, at that level of significance, we cannot reject a two-factor model that implies that J apanese and U.S. market risks are priced identically across countries when the Nikkei or the EAFE indices are used. We view this evidence as supportive of the notion of international integration among equity markets.

The paper proceeds as follows. The estimated model is introduced in Section 2. Section 3 presents the main empirical results. Section 4 investigates the robustness of the results to alternative econometric specifications and returns measurement intervals. Section 5 presents some concluding remarks.

\section{The Model}

We assume that:

(A1) Markets are internationally integrated.

(A2) Investors are period per period mean-variance optimizers in a common numeraire, which we take to be the U.S. dollar.

(A3) The aggregate relative risk aversion, $\lambda=\sum_{i=1}^{N} \lambda_{i t} W_{i t} / \sum_{i=1}^{N} W_{i t}$, is constant, where $\lambda_{i t}$ is the $i$-th individual's relative risk aversion and $W_{\text {it }}$ is his wealth at time $t$.

Assumption (A1) implies that assets with the same risk have the same expected excess returns irrespective of where the assets are traded. Assumption (A2) ensures that the capital asset pricing model holds. The assumption 
of a common numeraire implies that there are no preferred currency habitats for individual investors. ${ }^{1}$ Assumption (A3) implies that the risk premium changes only when the volatility of the market portfolio changes.

An alternative to assumption (A2) used in some of our tests is:

(A2') Investors use the currency of their home country as the numeraire.

Assumption (A2') corresponds to a world where the exchange rate reflects changes in the relative price of goods across countries and investors consume different baskets of goods in different countries. With this assumption, the world market portfolio of stocks is a portfolio where each stock position is financed in the country in which the stock is traded. Hence, the excess returns on a stock equal the returns of that stock in its own currency net of the returns of the risk-free asset in that currency. The interpretation of these own-currency returns is that they are equal to dollar returns hedged against currency risk with a hedge ratio of one - i.e., one goes short one unit of foreign currency for each purchase of one unit of foreign currency stock. This approach, pioneered by Solnik (1974), leads to a linear pricing relation between expected own-currency excess returns and their conditional covariance with the world market portfolio of own-currency excess returns. ${ }^{2}$

With these assumptions, we have:

$$
E\left(R_{m t+1}-R_{0 t+1} \mid \Omega_{t}\right)=\lambda \operatorname{Var}\left(R_{m t+1}-R_{0 t+1} \mid \Omega_{t}\right)
$$

where $E(\cdot)$ is the conditional expectation operator, $\Omega_{t}$ is the investors' information set at $t, R_{m t+1}$ is the return on the world market portfolio from $t$ to $t+1$, and $R_{0 t+1}$ is the risk-free rate for the same period of time. $\operatorname{Var}\left(R_{m t+1}-R_{0 t+1} \mid \Omega_{t}\right)$ is the conditional variance of the excess return on the

\footnotetext{
${ }^{1}$ See Adler and Dumas (1983) and Stula (1983) for reviews of the literature on international asset pricing and discussions of the role of preferred currency habitats.

2 There is no theoretical reason for the hedge ratio of one to be the minimum-variance hedge. When it is not, Sercu (1980) shows that the appropriate returns are those of self-financing portfolios of stocks hedged against exchange rate risk using the minimumvariance hedge. Bailey, $\mathrm{Ng}$ and Stulz (1992) provide evidence, however, that a hedge ratio of one cannot be improved upon for the Nikkei 225 by using conditional minimum-variance hedge ratios.
} 
world market portfolio for the period $t$ to $t+1$ given the information set $\Omega_{t}$. With assumption (A2), all excess returns are computed in dollars, whereas with the preferred currency habitats assumption (A2'), excess returns are own-currency returns, so that the excess return on the market portfolio is a weighted average of own-currency returns.

Using the capital asset pricing model and equation (1), we have:

$$
E\left(r_{d t+1} \mid \Omega_{t}\right)=\lambda \operatorname{Cov}\left(r_{d t+1}, r_{m t+1} \mid \Omega_{t}\right)
$$

where lower-case $r$ denotes excess returns and $\operatorname{Cov}\left(r_{d t+1}, r_{m t+1} \mid \Omega_{t}\right)$ is the conditional covariance of the excess return on the U.S. domestic market portfolio with the excess return on the world market portfolio.

The return on the world market portfolio can be written as:

$$
r_{m t+1}=w_{d t} r_{d t+1}+\left(1-w_{d t}\right) r_{f t+1}
$$

where $w_{d t}$ is the capitalization of the U.S. market portfolio as a fraction of world wealth at time $t, r_{d t+1}$ is the excess return on the U.S. domestic market portfolio and $r_{f t+1}$ is the excess return on the foreign market portfolio.

Using equation (3), (2) can be rewritten as:

(4) $E\left(r_{d t+1} \mid \Omega_{t}\right)=\lambda\left[w_{d t} \operatorname{Var}\left(r_{d t+1} \mid \Omega_{t}\right)+\left(1-w_{d t}\right) \operatorname{Cov}\left(r_{d t+1}, r_{f t+1} \mid \Omega_{t}\right)\right]$

In this paper, we focus on equation (4). If the U.S. market portfolio equals the world market portfolio, the weights become $w_{d t}=1$ for all $t$ and equation (4) reduces to the relation examined by French, Schwert and Stambaugh (1987). If the returns of the U.S. market portfolio are not related to the returns of the market portfolio of non-U.S. assets, equation (4) still differ8 from that of French, Schwert and Stambaugh (1987) since the conditional variance of the U.S. market portfolio is multiplied by the weight of the U.S. market portfolio in the world market portfolio.

With daily data from a single country, equation (4) has a straightforward interpretation because it corresponds to a portfolio strategy that can be easily 
implemented: buy the market portfolio at the close of trading and hold it until the next day's close of trading. With daily data from several countries, the trading hours generally do not overlap in calendar time. Using close-to-close returns for each country, it is not possible to implement directly a portfolio strategy of buying the world market portfolio at the close of U.S. trading at time $t$ and selling it at the close of U.S. trading at time $t+1$ because the foreign markets typically close before the U.S. market. To reduce the problem created by non-synchronous trading hours, one could use returns measured over longer periods of time, so that the non-overlapping period becomes a smaller fraction of the measurement interval. We choose instead to use daily data and address the problem of non-synchronous trading hours directly. Our use of daily data has two motivations. First, the period for which it is reasonable to investigate the effect of foreign stock markets on the U.S. risk premium is reasonably short, so that our tests would lack power with infrequently sampled data. Since existing tests of international asset pricing models that focus on stock returns use monthly data, the use of daily data is a contribution of this paper to the international asset pricing literature. $^{3}$ Second, the results of French, Schwert and Stambaugh (1987) that are most supportive of the positive relation between conditional expected excess returns and conditional variances are obtained using daily returns.

In using daily returns, we consider an investor who makes his portfolio decisions at the close of trading in the U.S. markets. When the investor forms his portfolio, he uses expected returns and the variance-covariance matrix of returns conditional on information available at that time. If we had foreign returns computed from the close of the U.S. market to the next close of the U.S. market, we would use these returns as part of the information set. Since foreign returns measured over the same calendar time as U.S. returns are not available, we have to model the joint dynamics of the U.S. and foreign returns to reflect the non-synchroneity of trading hours. Specifically, at the close of the U.S. market the investor knows the return on the U.S. market and the return on the foreign market at its close earlier in the calendar day. Since

\footnotetext{
${ }^{3}$ Engel and Rodriguez (1989) and Giovannini and Jorion (1989) use weekly data but test asset pricing models using returns on foreign currencies rather than on foreign stocks. Chang, Pinegar and Ravichandran (1991) use daily returns in a study of the integration of European equity markets where the problem of non-synchronous trading is not significant.
} 
the U.S. market closes after most foreign markets, part of the next day's return of the foreign market has already accrued when the investor makes his portfolio decision. As long as contemporaneous returns on the domestic and foreign markets are correlated, the investor can use today's U.S. return to improve his forecast of tomorrow's foreign return. Our approach accounts explicitly for this correlation.

The information in the U.S. close-to-close return today about the next day's foreign return gives the appearance that foreign market returns are predictable using the previous day's U.S. return. This predictability is spurious, however, since it cannot be exploited through a portfolio strategy if foreign markets are efficient. The foreign return does not contain similar information about the next calendar-day U.S. return since on the previous calendar day the foreign markets closed before the U.S. market and hence the information in the foreign returns is incorporated in the previous day U.S. return. ${ }^{4}$

Given that the lack of synchroneity in trading hours affects our modeling strategy, it is important to make sure that it does not affect our results. We therefore set up two further experiments. First, we know that as the measurement interval is lengthened, the lack of synchroneity becomes less important. Our robustness tests indeed show that our result that there is a significant foreign effect on the U.S. risk premium holds if we use longer measurement intervals for the returns. Second, we demonstrate that it holds if we use open-to-open U.S. returns and hence allow the investor to form his expectations at the open of U.S. markets.

In the following, we assume that the information set of investors, $\Omega_{t}$, is proxied by a set of instruments that includes only past returns of the U.S. and the foreign portfolios for the sample period. ${ }^{5}$ We therefore propose the parameterization:

\footnotetext{
1 If we had used the close of trading in foreign markets as the time when the investor make his portfolio decision instead, today's foreign return would be useful to forecast the same calendar day U.S. return, but the U.S. return would not be useful to forecast tomarrow's foreign return. Hence, in this case, the returns dynamics would have to be modelled differently.

${ }^{5}$ This is in contrast to the instrumental variables appraach of Harvey (1991) that conditions the market risk premium on a set of macroeconomic variables.
} 
(5a) $r_{d t+1}=a_{d}+\beta_{d v} w_{d t} h_{d t+1}+\beta_{d c}\left(1-w_{d t}\right) h_{c t+1}+\theta_{d 1} \epsilon_{d t}+\theta_{d 2} \epsilon_{d t-1}+\epsilon_{d t+1}$

(5b)

$r_{f t+1}=a_{f}+\beta_{f \cup} w_{f t} h_{f t+1}+\beta_{f c}\left(1-w_{f t}\right) h_{c t+1}+\theta_{f 1} \epsilon_{f t}+\theta_{f 2} \epsilon_{f t-1}+\phi_{f} \epsilon_{d t}+\epsilon_{f t+1}$

where the conditional variances, $h_{f t+1}$ and $h_{d t+1}$, and covariances, $h_{c t+1}$, depend only on past returns. The specification for each country allows the returns to depend on two lagged disturbances to incorporate the effects of infrequent trading on the dynamics of the index returns. ${ }^{6}$ We also allow the foreign returns to depend on one lagged disturbance of the domestic returns through $\phi_{f}$ to take into account the lack of synchroneity in trading hours. As explained above, with our timing conventions, foreign returns have no information for domestic returns since, on a given calendar day, the information in foreign returns is incorporated in domestic returns before the close of trading of domestic markets; hence, there should be no $\phi_{d}$ in the domestic returns equation. ${ }^{7}$

An important element in the empirical implementation of the model is the specification of the dynamics of the conditional variances and covariances over time. We use a general specification drawn from the ARCH process originally proposed by Engle (1982), which allows the conditional covariance matrix to be related to its own past values and past squared disturbances. We posit the following general process:

$$
\underline{\epsilon}_{t+1} \sim N\left(0, \underline{\underline{H}}_{t+1}\right) \text { and } \underline{\underline{H}}_{t+1}=\left[\begin{array}{ll}
h_{d t+1} & h_{c t+1} \\
h_{c t+1} & h_{f t+1}
\end{array}\right]
$$

$$
\underline{\underline{H}}_{t+1}=\underline{\underline{P}}^{\prime} \underline{\underline{P}}+\underline{\underline{F}}^{\prime} \underline{\underline{H}} t \underline{\underline{F}}+\underline{\underline{G}}^{\prime} \underline{\underline{\epsilon}}_{t} \underline{\epsilon}_{t}^{\prime} \underline{\underline{G}}
$$

${ }^{6}$ Stoll and Whaley (1990) show how the effects of infrequent trading and bid/ask spreads can cause stock index returns to follow an ARMA-type process. See also Muthuswamy (1990).

${ }^{7}$ Our method of addressing the non-synchroneity in trading hours could be improved in future research since we omit the covariance attributable to the unanticipated return on the foreign market between the close of that market and the close of the U.S. market because that return is unobservable. Instead, we implicitly assume that the true covariance is a constant proportion of the estimated covariance. If this asumption is incorrect, we would expect our results to be sensitive to alternative measurement int ervals, but we show in section 4 that they are not. 
where $\underline{\underline{H}}_{t+1}$ denotes the $2 \times 2$ variance-covariance matrix conditional on information as at time $t$ and $\epsilon_{t+1}$ denotes the vector of disturbances from equations (5a)-(5b). $\underline{\underline{P}}$ is an upper triangular matrix of coefficients, whereas $\underline{\underline{F}}$ and $\underline{\underline{G}}$ are free matrices of coefficients. This model was originally proposed by Baba, Engle, Kraft and Kroner (1989) (BEKK). The important feature of this specification is that it builds in sufficient generality allowing the conditional variances and covariances of the two stock markets to influence each other and, at the same time, does not require a large number of parameters to be estimated ( 11 for the bivariate system used here). Even more importantly perhaps, the BEKK process guarantees that the coefficient matrices in the system are positive definite. To see the level of generality we gain by implementing this specification, we can contrast it with the multivariate ARCH model adopted by Bollerslev, Engle and Wooldridge (1988) (BEW), where the conditional variances depend only on past squared residuals and covariances on past products of disturbances. The important crose-market effects, highlighted by Hamao, Masulis and $\mathrm{Ng}$ (1990) for the national stock markets of the U.S., U.K. and Japan, are ignored in the BEW specification. A more general BEW process could be specified to capture these effects but positive semi-definiteness of the conditional covariance matrix in that system is no longer assured. We discuss estimation results with alternative processes in section 4 .

\section{Description and Interpretation of Empirical Results}

\subsection{Data}

We use three indices for non-U.S. assets. The first index is the Nikkei 225 Stock Average. The data for the Nikkei 225 index is collected from the Asian Wall Street Journal and the exchange rates used to obtain dollar returns are collected from the Journal also. The Nikkei 225 is a price-weighted index of stocks traded in the first section of the Tokyo stock market. For this index, we have data from January 3, 1978 to December 31, 1989. In addition to the Nikkei 225 index, we used two value-weighted indices published in Morgan Stanley's Capital International Perspectives that are available from January 3, 1980 to December 31, 1989. These indices are the Morgan Stanley Japan 
index in yen and the Morgan Stanley EAFE index in dollars. We use the indices only on calendar days when they are available in both countries and make no distinction between single and multiple-day returns. The Morgan Stanley Japan index is the Japanese component of EAFE and hence is a value-weighted index. The EAFE index does not include all stocks for each market, since it generally ignores small capitalization stocks. However, it is widely used by practitioners as a benchmark for the performance of non-U.S. stocks and internationally diversified index funds generally try to replicate the performance of that portfolio. It includes no adjustment for cross-holdings in Japan and other countries, so that it may give more weight to Japan than is warranted, as argued by McDonald (1989) and French and Poterba (1991).

Table 1 provides summary statistics for the data, including the crosscorrelations among the various portfolio excess returns. The U.S. index and dollar-denominated foreign equity index excess returns are obtained using the three-month U.S. Treasury bill yields; those for the yen-denominated Nikkei 225 index are computed with the three-month Gensaki interest rate. Panel A indicates that the excess returns series exhibit significant negative skewness for the S\&P 500 and the Nikkei yen excess returns and generally positive excess kurtosis. These results suggest that the returns distribution deviates from normality. The Kolmogorov $\mathrm{D}$ statistic and tests based on Bera and Jarque (1982) confirm this formally. The autocorrelation coefficients are exhibited in Panel $B$ for the raw excess returns and squared returns series. The significant positive and declining autocorrelations for the squared series indicates some second-order dependence that the GARCH models in this study seek to capture. Finally, the cross-correlations between the S\&P 500 returns and those of the various foreign index returns are shown in Panel C. The significant contemporaneous lead correlations from U.S. to foreign stocks in the raw returns reflect the lack of synchronization of trading hours for the respective markets. Equations $(5 a, b)$ of the model proposed in the previous section attempt to control for this effect. More interestingly, the cross-correlations computed for the squared returns series suggest significant cross-market dependence in the volatility. Again, the dynamics of the conditional covariances applying the BEKK process of equation (6) can capture such cross-market dependence in the volatility of the returns. 
Equations $(5 \mathrm{a}, \mathrm{b})$ require computation of market weights. We obtain these weights from Morgan Stanley's Capital International Perspectives. Since the weights are published quarterly, we use the beginning of quarter weights reported by Morgan Stanley and compute the weights within each quarter by adjusting dynamically the beginning of quarter weights using the realized returns on the indices. For each quarter, we extend the interpolation to the beginning of the next quarter and compare the weights that result from our method to those reported by Morgan Stanley. In this comparison, the reported weights are always very close to the predicted weights.

\subsection{Empirical Results}

Panel A of Table 2 reproduces estimates of equations (5a,b) that use, respectively, the dollar-denominated excess returns on the Nikkei 225 index, the yen-denominated excess returns on the Nikkei 225 index and the Morgan Stanley Japan index and the dollar-denominated excess returns on the EAFE index as the returns on the foreign market portfolio. The estimates are obtained using dummy variables in the returns equations (5a)-(5b) for four days of October 1987, namely October 16, 19, 20 and 21, since it appears that the distribution of returns on these days differs dramatically from the distribution of returns for the other days in our sample. The point estimates obtained without the dummy variables for the parameters of interest are quite similar to those reported here, but statistical inference becomes more complicated because of the serious departures from the normality assumption.

The estimates of the equation for U.S. returns with the dollar returns of the Nikkei 225 as the foreign market portfolio returns show that the conditional covariance of the U.S. returns with the Nikkei return has a significant positive effect on U.S. conditional expected returns, but that the conditional variance of the U.S. returns has no effect. This result holds whether one uses standard $t$-statistics or the alternative $t$-statistics robust to departures from normality suggested by Bollerslev and Wooldridge (1990). ${ }^{8}$ Hence, this result provides support for the hypothesis that the U.S. risk premium is determined on global markets during the sample period. The lack of significance of the

\footnotetext{
${ }^{8}$ Because of the large sample size of this analysis, the appropriate criteria for statistical significance for sample statistics and estimated coefficients are unclear. We highlight throughout the text and tables, critical values at conventional significance levels but caution the readers that a more conservative cutoff may be appropriate.
} 
coefficient on the variance is surprising. Since the conditional variance and covariance have a significant correlation ( 0.57 if we use the dollar-denominated Nikkei returns), one might be tempted to attribute the lack of a significant effect of the conditional variance to multicollinearity. However, if we estimate a univariate model for the U.S. returns for our sample period, the coefficient on the variance is not significant either. A more plausible explanation is that, if the returns are measured with error, the error in the returns decreases the precision of our variance estimate more than it decreases the precision of our covariance estimate since returns squared involve taking the square of the error whereas products of domestic and foreign returns involve multiplying two errors that are imperfectly correlated. The estimates obtained with the yen-denominated excess returns of the Nikkei 225 are qualitatively similar to those obtained with dollar-denominated returns.

The estimates using the Morgan Stanley Japan index and EAFE as foreign market portfolios are consistent with those obtained using the Nikkei 225. In both equations, the covariance has a positive coefficient that is significantly different from zero using standard $t$-statistics. Using robust $\boldsymbol{t}$-statistics, the covariance coefficient is significant at the 0.10 level for the Morgan Stanley Japan index, but is insignificant at the same level for the EAFE index. The point estimates of the covariance coefficients are almost the same for the equations using the Nikkei 225 and EAFE. The variance of the U.S. has a positive but statistically insignificant coefficient in both equations.

Table 2 also reports results for foreign excess returns. The results are not completely symmetric to those for the U.S. When we use the dollar excess returns on the Nikkei, the covariance with the U.S. returns has a positive but insignificant effect on the expected excess returns of the index, but the variance of the Nikkei has a significant positive coefficient. The same result holds for the equation estimated with the yen-denominated excess returns on the Nikkei, except that in this case the covariance has a significant positive coefficient with the standard $t$-statistic and an insignificant coefficient with the robust $t$-statistic. With the Morgan Stanley Japan and EAFE indices, the variance of the foreign index has an insignificant positive coefficient; the covariance has a negative insignificant coefficient for the EAFE but a positive 
significant coefficient for the Morgan Stanley Japan index at the 0.05 level using the standard $t$-statistic and at the 0.10 level using the robust $t$-statistic.

For all indices, we tested the hypothesis that the expected returns are determined in the home country - i.e., that Japanese expected returns do not depend on the covariance of Japanese returns with U.S. returns and that U.S. expected returns do not depend on their covariance with Japanese returns. Though the results are not reported, this hypothesis is easily rejected for all indices. Consequently, irrespective of the index used to proxy for foreign stocks, the covariance of foreign stock returns with domestic stock returns has an important effect on the expected returns on domestic stocks.

Table 2 also provides measures of the fraction of the total variation of returns captured by our explanatory variables. Whereas the fraction of the total variation explained for the U.S. returns, denoted $R_{1}^{2}$, is small but respectable given the difficulty of forecasting daily returns, it would be virtually negligible if we ignored the international effect presented in this paper. For instance, if we set the coefficient on the conditional covariance equal to zero in the U.S. returns equation when the dollar return on the Nikkei 225 is used as the foreign return, the $R_{1}^{2}$ falls from $1.16 \%$ to $0.29 \%$; in contrast, it falls to only $0.94 \%$ if we set the coefficient on the conditional variance equal to zero and to $0.25 \%$ if both coefficients on conditional variance and covariance equal zero. Note that if the coefficients for the conditional variance and covariance are are set to zero, the $R^{2}$ captures the proportion of the total variation that is due to just the lagged moving average terms which are posited to capture the effects of asynchronous trading of the component stocks in the domestic and foreign market indexes. Further, the $R^{2}$ for the U.S. returns equation in this case is substantially larger than that for a simple univariate model $(0.28 \%)$. Although the fraction of the total variation explained for the foreign returns, $R_{2}^{2}$, is much larger than the fraction explained for the U.S. return, it becomes comparable to the fraction explained for the U.S. return if $\phi_{f}$ is set equal to zero, as one would expect.

Figures 2 and 3 plot, respectively, the conditional expected excess returns and conditional variances and covariances for the U.S. when the foreign index uses dollar-denominated returns on the Nikkei 225 and show that all the series exhibit substantial variation over time. For the U.S. returns, the conditional 
daily expected excess returns have a standard deviation of $0.09 \%$ and a mean of $0.04 \%$, whereas the unconditional daily excess returns have a mean of $0.025 \%$ and a standard deviation of $0.97 \%$. Further, the sample mean and standard deviation of the daily conditional variance are, respectively, 0.94 and 0.54 , whereas for the covariance they are 0.09 and 0.22 . As a measure of the economic significance of the international effect on the U.S. risk premium, our results suggest that a doubling of the conditional covariance from its mean value of 0.09 to 0.18 doubles the conditional expected excess return on the U.S. portfolio from $0.04 \%$ to $0.075 \%$. Note that a doubling of the conditional covariance is an increase of slightly less than half the standard deviation of the conditional covariance, indicating that such an increase is not unusual. Similarly, a doubling of the conditional risk premium is also an increase of slightly less than half its standard deviation.

Panel B of Table 2 presents the estimates of the coefficients of the dynamics of the covariances from equation (6). The individual coefficient estimates are difficult to interpret but the significance of the diagonal coefficients of the $\underline{\underline{F}}$ and $\underline{\underline{G}}$ matrices suggest that the GARCH effects are pervasive and strong. Moreover, most of the off-diagonal coefficients are also significant. This result confirms the evidence of Hamao, Masulis and $\mathrm{Ng}(1990)$ that modelling the cross-market dependence in the conditional volatility of U.S. and foreign stock returns is important.

Table 3 provides evidence on whether the coefficients on conditional variances and covariances of Table 2 conform to the predictions of the international CAPM (ICAPM). The ICAPM implies that all the $\beta$ coefficients of Table 3 should be equal. ${ }^{9}$ Table 3 presents estimates of the models of Table 2 with the $\beta$ coefficients constrained to be equal. Irrespective of the foreign portfolio used, the world price of risk is positive and significantly different from zero. With the ICAPM, the estimate for the price of risk corresponds to the representative investor's coefficient of relative risk aversion. The estimates for this coefficient vary from 9.6 to 18.1 depending on the foreign portfolio used. Although the estimate is high, it is not altogether

\footnotetext{
${ }^{9}$ In footnote 7 , we argue that our approach may generate measures that understate the true covariance. If it does, our test of the ICAPM is more conservative because our estimate of the covariance effect, $\beta_{d c}$, is biased upwards and hence away from the other $\beta_{i j}$ coefficients.
} 
unreasonable in light of the literature. For instance, although greater than the estimates obtained by Friend and Blume (1975) and Hansen and Singleton (1983), it is substantially smaller than those presented by Wheatley (1988) and comparable to those of Harvey (1991) in tests of international asset pricing models.

The last column of Table 3 presents $\chi^{2}$ statistics that compare the unrestricted version of the model to the restricted version. The restricted version cannot be rejected at the 0.05 level. However, one might argue that a more conservative approach is warranted since we have only two assets. If we use the 0.10 significance level as our benchmark, we cannot reject the ICAPM when the foreign portfolio is EAFE or Morgan Stanley Japan; however, we can reject the ICAPM if the foreign portfolio is the Nikkei, whether we use a dollar-denominated or a yen-denominated Nikkei. This limited success with the Nikkei may reflect the fact that the Nikkei is not a value-weighted index and hence gives more weight to small stocks. Hence, whereas our results are supportive of the ICAPM, the lack of rejection may also reflect the limited power of our tests.

\section{Further Tests}

In this section, we first relate the results to earlier work. We then examine the robustness of the results concerning the international effect on the risk premium and conclude with more tests of the international capital asset pricing model.

\subsection{Relation to Previous Work}

French, Schwert and Stambaugh (1987) relate conditional expected returns on the S\&P 500 index to the conditional volatility of the index using a univariate GARCH-in-mean process. They find that conditional expected returns are positively related to conditional volatility. Their test is not nested in the test discussed in Section 3 since they estimate the process followed by the S\&P 500 using only U.S. data. We replicated the French, Schwert and Stambaugh (1987) study over our sample periods for the U.S. and Japan, but do not present the estimates here. ${ }^{10}$ Over our sample periods, the result

\footnotetext{
${ }^{10}$ French, Schwert and Stambaugh (1987) estimate a GARCH(1,2) process, whereas the
} 
obtained by French, Schwert and Stambaugh (1987) does not hold for U.S. returns as the conditional expected returns on the U.S. market portfolio are not significantly related to the conditional variance of the returns of that portfolio. ${ }^{11}$ In contrast, however, there is evidence that the conditional expected return of the foreign indices is related to their conditional volatility. ${ }^{12}$ These results are consistent with the results obtained in Table 2 since in that table the coefficient of the conditional volatility of the U.S. index in the U.S. returns equation was insignificant, whereas the coefficient on the conditional volatility of the foreign index in the foreign returns equation was significant for the Nikkei 225 whether denominated in yen or in dollars.

Bollerslev, Engle and Wooldridge (1988) investigate a trivariate conditional CAPM that includes three portfolios, namely a portfolio of stocks, a portfolio of long-term bonds and a portfolio of short-term bonds. Their approach is similar to ours in that they model the joint distribution of returns using a GARCH-in-mean process. However, they posit dynamics for the variance-covariance matrix of returns that allow variances and covariances to depend only on their past values, in contrast to the dynamics we posit which allow for additional cross-market dependence in variances and covariances. They find a positive price of covariance risk, which is a result analogous to our finding of a positive price of risk in the equations estimated in Table 3.

Existing research on international asset pricing has focused mostly on unconditional returns. The most notable exception is Harvey (1991), who allows for the price of risk to change over time in a pooled cross-sectional timeseries test using monthly returns on a variety of countries. He models asset returns dynamics with instrumental variables and uses a generalized methodof-moments estimator to test the restrictions of the international CAPM. He finds evidence that the world price of covariance risk is not constant and rejects the hypothesis that Japanese stocks are priced according to the international CAPM.

estimates reproduced in this paper are obtained for a $\operatorname{GARCH}(1,1)$ process. None of the conclusions of this paper are affected if this alternative specification is introduced.

${ }^{11}$ Glosten, Jagannathan and Runkle (1989) demonstrate the instability of the relation estimated by French, Schwert and Stambaugh (1987) for different specifications of the conditional variance.

${ }^{12}$ See Chan and Karolyi (1991) for similar findings on the Nikkei 225 Stock Average index. 


\subsection{Robustness and Stability of the International Effect}

\subsubsection{Synchroneity}

As discussed in Section 2, the use of daily data raises the issue of lack of synchroneity in the returns measurement intervals across countries. There is no way of eliminating this lack of synchroneity, but by using longer measurement intervals, its importance should fall since, as the interval length increases, the fraction of the interval for which returns are observed on both markets also increases. Hence, one way to evaluate the robustness of our results and the appropriateness of our approach to deal with the non-synchroneity in trading hours is to reestimate our equations on longer observation intervals. Results with the dollar-denominated Nikkei excess returns are reproduced in Table 4 for two-day, three-day and five-day returns. It is clear that our conclusion that the conditional U.S. expected excess returns are positively related to the conditional covariance of the U.S. excess returns with foreign market returns is robust to an increase in the length of the observation interval. Importantly, as the returns are computed over longer periods of time, the apparent predictability of foreign returns from U.S. returns due to the overlapping of the measurement intervals disappears, as expected. ${ }^{13}$

The lack of synchroneity in trading times leads to lower estimates of conditional covariances since the same information can be incorporated in different indices on different calendar days. Whereas we attempt to estimate conditional covariances that proxy for the conditional covariances that would prevail if trading were synchronous across countries, our approach is imperfect since it ignores part of the covariance because of the unobservability of foreign returns from the close of the foreign market to the close of the U.S. When returns are measured over longer horizons, the non-overlapping part of the returns becomes a smaller fraction of the measurement interval, so that the conditional covariance should increase. ${ }^{14}$ This difference between long-

\footnotetext{
${ }^{13}$ As the measurement interval is extended, however, one would expect the extimates to become less precise because the number of independent observations falls. Further, our regression framework becomes less appropriate since longer horizon returns may have difierent time-series properties than shorter horizon returns. Nevertheless, in a regreasion not reproduced here, we extended the measurement interval to ten days and found that the $\beta_{d c}$ coefficient estimate is aleo statistically dignificant with a value of 142.8

14 See Bailey and Stulz (1990) for evidence on how covariance estimates between U.S. and Japanese returns depend on the mesurement interval because of the lack of synchroneity
} 
run and short-run conditional covariances does not affect our conclusion that there is an international effect on the U.S. risk premium since that effect is robust to increases in the measurement interval. Although the coefficient $\beta_{d c}$ falls when returns are measured over longer intervals, this decrease is not significant.

Another way to reduce the effects of the lack of synchroneity in trading hours between the two countries is to employ open-to-open U.S. returns with close-to-close Japanese returns. Transactions data of intraday quotes on the S\&P 500 from the Chicago Mercantile Exchange were available to us for the 1984 to 1989 subperiod. In Table 4, we provide estimates of our model where U.S. returns are computed from prices one hour after the market opening. We use returns one hour after the opening because opening returns have different properties from other returns since an opening price included in the index could be a price from the previous day. ${ }^{15}$ These estimates fully support the conclusions drawn from the estimates that use the close-to-close returns. Interestingly, these estimates correspond to a subperiod that is approximately the second half of our sample of Nikkei data. Yet, for this second half, the coefficient for the international effect is essentially the same as for the whole sample when we use close-to-close returns.

\subsubsection{Conditioning Information}

The model estimated in Table 2 includes lagged disturbances to take into account the effects of non-synchronous trading of component stocks in the index on the measurement of stock index returns. The significant positive effect of the first lagged disturbance is consistent with our infrequent trading motivation for the inclusion of these lagged disturbance terms. ${ }^{16}$ Ignoring this lag structure may have the effect of spuriously increasing the importance of the international effect. This is shown in Table 4 where we provide estimates of a version of our model that excludes these lagged disturbances. We also

\footnotetext{
in trading hours.

${ }^{15}$ See Lin, Engle and Ito (1991) for evidence of the importance of this distinction for the measurement of spillover effects across markets.

${ }^{18}$ One would expect the foreign indice to have more infrequent trading. It is therefore expected that the first lagged disturbance should have a greater effect on the foreign returns equations. It is puzzling, however, that the first lagged disturbance should have a greater effect in the foreign equation using the value-weighted Morgan Stanley index than it does on the foreign equations using the price-weighted Nikkei 225.
} 
estimated the model with $\phi_{f}$ set equal to zero. These estimates, though not reproduced here, show that the international effect appears to be stronger when $\phi_{f}$ is not included. Another alternative we examined (but do not report) was one where we rolled back the investors' conditioning information by one day, so that $\epsilon_{t-1}$ replaced $\epsilon_{t}$ in equations (5) and (6); this approach still produced similar results. Rolling back the conditioning information set has three purposes. First, it is an attempt to see how the results change with changes in the information set. ${ }^{17}$ Second, it shows how the results are affected when the spurious predictability of foreign returns due to the lack of synchroneity in trading hours is explicitly removed. Finally, it shows that the covariance effect found for the U.S. expected excess returns is unlikely to be due to asynchronous trading in the S\&P 500 stock index. When rolling back the conditioning information by one calendar day, the conditional covariance estimate does not incorporate information from the previous day and is not likely to be affected by information that may not have been fully incorporated into stock prices because of asynchronous trading. In summary, our results on the existence of an international effect are not sensitive to the lag structure included in the estimated models.

\subsubsection{Day-of-the-Week Effects}

The estimates in Table 2 use trading time as unit of measurement of returns - i.e., all returns are computed from the end of a trading period to the end of the next trading period. In Table 4, we provide estimates of the model where we allow different intercepts in the expected excess returns and the variance-covariance equations for multiple calendar days because of weekends or holidays. The results are similar - although the robust $t$-statistic on the international effect falls to 1.59. However, in this case, the coefficient on the first lagged disturbance becomes strongly significant for both countries and the coefficient in the Nikkei equation for the lagged U.S. return increases in value.

\subsubsection{Alternative Specifications}

Multivariate GARCH is a full information maximum likelihood (FIML)

\footnotetext{
${ }^{17}$ Note that our econometric models attempt to approximate (1). These models are approximations because we condition on an observed information set that is necessarily coarser than $\Omega_{t}$, the true information set.
} 
estimation method. Although it is more efficient than conventional instrumental variables methods, its parameter estimates can suffer from instability if misspecified. To investigate whether our inference about the foreign effect is sensitive to these estimation methods, we also employ an alternative twopass procedure. We first estimate the model assuming constant conditional means to generate the conditional variance and covariance series and then regress the excess returns on the conditional variances and covariances using a seemingly unrelated regression (SUR) model. This approach leads to similar conclusions as the GARCH-in-mean approach. In particular, for the model with dollar-denominated Nikkei returns, using this two-pass approach, the coefficient $\beta_{d c}$ is $\mathbf{5 4 . 0 2}$ with a heteroscedasticity-consistent $t$-statistic of 3.10.

Since equation (6) for the dynamics of the variance-covariance matrix is a projection equation without theoretical foundation, we also estimated our model using alternative specifications for these dynamics. We re-estimated the model using equation (6) without imposing the BEKK constraints on the coefficient matrices. This unrestricted version does not ensure that the variance-covariance matrix is positive semi-definite. With this version, the point estimates for the variance and covariance effects on the mean returns were similar to those from the BEKK process but less precise. This was likely due to the larger number of parameters required for implementation. We also estimated our model using the constant correlation model of Schwert and Seguin (1990) and the Bollerslev, Engle and Wooldridge (1988) process. The coefficients are again similar to those reported in Table 2 except for the coefficient on the conditional covariance in the U.S. returns equation which is 174 (with standard (robust) $t$-statistic of $1.81(1.40)$ ) for the Bollerslev, Engle and Wooldridge process and 284 (with standard (robust) $t$-statistic of $1.44(1.40)$ ) for the Schwert and Seguin model. Though these additional formulations impose strong restrictions on the covariance dynamics - constant correlation in Schwert-Seguin and no cross-market spillover effects in BEW - the covariance effect is still shown to be important.

The market weights used in the estimation are constructed dynamically from quarterly observations provided by Morgan Stanley's Capital International Perspectives. We investigated the sensitivity of our results to the esti- 
mates for the market weights by re-estimating the model assuming constant weights of 0.5 . These estimates are reproduced in Table 3 and show that the international effect holds strongly with constant market weights.

\subsubsection{Residual Diagnostics}

Table 5 reports some residual diagnostic tests for the bivariate and univariate models estimated in this paper. Panel A presents the cross-sectional and time-series statistics for the scaled residuals of the bivariate models for the U.S. and foreign excess returns. The residuals are scaled by the square root of the conditional variance, $\frac{\varepsilon_{i 1}}{\sqrt{h_{i 1}}}$. Tests indicate that the average standardized residuals are small compared to their standard deviation (using conventional $t$-statistics, they would not be significantly different from zero), suggesting that we should not be overly concerned that overfitting might lead to a bias in our estimates of the conditional means. The significant positive excess kurtosis and negative skewness observed for the raw returns in Table 1 are reduced considerably. However, the Kolmogorov D and Bera-Jarque test statistics for normality still indicate significant deviations from normality, suggesting that our focus on $t$-statistics robust to deviations from normality is warranted. ${ }^{18}$ Panel $\mathrm{C}$ demonstrates that the cross-correlation patterns noted in the raw returns of Table 1 are mostly absorbed by the bivariate model. In general, only contemporaneous correlations between the foreign and U.S. returns appear to be significantly different from zero.

\subsection{Additional Asset Pricing Tests}

In Table 3, we are unable to reject the ICAPM at the 0.05 level, but can do so at the 0.10 level for the Nikkei indices. A better way to understand our results is to compare them to tests of simple two-factor models. One can think of two possible such models in the context of this paper. First, it could be that there are barriers to international investment that limit the ability of investors to take advantage of the benefits of international diversification. We refer to this version as the "segmented" model. Second, investors might not use a mean-variance framework, but rather hold securities also for the

\footnotetext{
${ }^{18}$ Neleon (1992) and Nelson and Foster (1991a,b) provide some conditions under which ARCH models may perform reasonably in estimating and even in forecasting conditional covariances even when some evidence of model misspecification (e.g., nomnormality in standardized residuals) remains.
} 
purpose of hedging against unanticipated changes in various state variables, which we call here the "hedging" model. In the latter case, we posit the domestic and foreign market excess returns as factor-mimicking portfolios.

With segmented markets, the price of risk can differ across countries. In Table 3, we report estimates of a model that allows the price of risk to differ across countries. In this model, the coefficients on the weighted conditional variances and covariances are constrained to be the same within countries, but not across countries. This model does not appear to perform better than the ICAPM. Hence, it does not seem to be the case that the weak performance of the ICAPM can be attributed to the existence of barriers to international investment.

In contrast, the hedging model's performance seems to be better than the performance of the ICAPM. With this model, the coefficients on the weighted domestic conditional variance (covariance) and the foreign weighted conditional covariance (variance) are constrained to be the same. At the 0.10 level, the hedging model is rejected only when we use the Morgan Stanley Japan index. These results suggest that more work on a multifactor hedging model could lead to a better understanding of how risky assets are priced in an international setting. Evidence by Cumby (1990) and Wheatley (1988) on the Stulz (1981) international consumption asset pricing model is supportive of this conjecture. Additional evidence is provided by Campbell and Hamao (1992) and Bekaert and Hodrick (1992) in their work showing that changes in expected returns can be captured by models with more than one latent variable.

So far, we have interpreted our tests of the international CAPM in terms of alternatives that posit that the risk of an asset is not measured simply by the conditional beta of the asset's returns relative to the world market portfolio. Since all our tests assume that the world relative risk aversion is constant, an alternative to the models studied in this section is one where the world relative risk aversion parameter changes over time. ${ }^{19}$ Harvey (1991) pursues this approach using instrumental variables in a generalized method-of-moments

\footnotetext{
${ }^{19}$ McCurdy and Morgan (1991) employ a multivariate GARCH framework that allows for a CAPM-type apecification with time variation in the conditional betas. They examine the risk premis in deviations from uncovered interest rate parity in weekly spot currency prices.
} 
framework. With daily data, an approach that models the dynamics for the price of risk explicitly will be difficult to implement because the instruments used in Harvey (1991) and related analyses are typically not observed daily. Nevertheless, in the spirit of Harvey (1991) we investigated the hypothesis that the price of risk changes during our sample period by allowing the price of risk to differ in the second half of our sample from the first half when the index uses dollar-denominated returns on the Nikkei 225 . We find that the price of risk is indeed significantly higher in the second half of the sample, suggesting that further research should extend our approach to model explicitly the time-variation of the price of risk.

\section{Concluding Remarks}

In this paper, we investigate the relation between the conditional expected excess returns on the S\&P 500 portfolio and its conditional risk as measured by its conditional volatility and its conditional covariance with the returns on some index of foreign stocks. We find that the conditional covariance of the S\&P 500 returns with the returns of foreign stocks is significantly positively related to the conditional expected excess returns of the S\&P 500 over 1978 to 1989 when the returns to foreign stocks are proxied by the returns of the Nikkei 225 index, Japan's Morgan Stanley index or, but less so, by the EAFE index. This result holds whether the model is tested using dollar-denominated excess returns or the yen-denominated excess returns for the Nikkei 225. In contrast, there is no significant relation between the conditional expected excess returns on the S\&P 500 and its conditional variance. We show that the international effect is economically significant \&ince an increase in the daily conditional covariance between U.S. and foreign returns that corresponds to half its sample standard deviation increases the daily U.S. risk premium by about $\mathbf{0 . 0 3 5 \%}$ or slightly less than one-half of its standard deviation.

Our result on the existence of an international effect on the U.S. risk premium is shown to be robust to alternative measurement intervals of the returns and to alternative econometric specifications. In particular, this effect holds even if we use two-, three- and five-day returns rather than daily returns 
and if we use open-to-open returns for the S\&P 500 rather than close-toclose returns. Further, our results hold if the elements of the conditional variance-covariance matrix obtained from the GARCH approach are used as explanatory variables in a two-pass approach using seemingly unrelated regression models.

We are unable to reject the international CAPM at the 0.05 level of significance, but can reject it at the 0.10 level when the Nikkei 225 index is used as the foreign index. It is generally the case that a two-factor model where the domestic and foreign indices proxy for unspecified factors performs better than the international CAPM. In particular, this two-factor model cannot be rejected at the 0.10 level for the Nikkei indices. Our tests are therefore supportive of the hypothesis that markets are internationally integrated over the sample period we consider. 


\section{References}

Adler, Michael and Bernard Dumas, 1983, International portfolio selection and corporation finance: A synthesis, Journal of Finance 46, 925-984.

Baba, Y., Robert F. Engle, D. F. Kraft and K. F. Kroner, 1989, Multivariate simultaneous generalized ARCH, working paper, University of California, San Diego.

Bailey, Warren, Edward Ng and René Stulz, 1992, Portfolio management and exchange rate risk: New theoretical and empirical perspectives on the hedging controversy, S. Khoury, (ed.), Recent Developments in Banking and Finance, Basil Blackwell, Oxford, UK.

Bailey, Warren, and René M. Stulz, 1990, Benefits of international diversification: The case of Pacific Basin stock markets, Journal of Portfolio Management, (Summer), 57-62.

Bekaert, Geert, and Robert Hodrick, 1992, Characterizing predictable components in excess returns on equity and foreign exchange markets, Journal of Finance, forthcoming.

Bera, Anil and C.M. Jarque, 1982, Model specification tests: a simultaneous approach, Journal of Econometrics 20, 59-82.

Bollerslev, Tim, 1986, Generalized autoregressive conditional heteroskedasticity, Journal of Econometrics 31. 307-327.

Bollerslev, Tim, Robert F. Engle, and Jeffrey M. Wooldridge, 1988, A capital asset pricing model with time-varying covariances, Journal of Political Economy 96, 116-131.

Bollerslev, Tim, and Jeffrey M. Wooldridge, 1990, Quasi-maximum likelihood estimation and inference in dynamic models with time-varying covariances, unpublished working paper, Northwestern University.

Campbell, John Y. and Yasushi Hamao, 1992, Predictable stock returns in the United States and Japan: A study of long-term capital market integration, Journal of Finance, forthcoming.

Chan, K.C. and G. Andrew Karolyi, 1991, The volatility of the Japanese 
stock market: Evidence from 1977-90, in W. Bailey, Y. Hamao and W. Ziemba, (eds.), Japanese Financial Market Research, North Holland Publishers.

Chang, E.C., J.M. Pinegar and R. Ravichandran, 1991, Latent variables tests of the integration of European equity markets, unpublished working paper, University of Maryland.

Cho, Chinhyung D., Cheol S. Eun, and Lemma W. Senbet, 1986, International arbitrage pricing theory: An empirical investigation, Journal of Finance 41, 313-330.

Cumby, Robert E., 1990, Consumption risk and international equity returns: Some empirical evidence, Journal of International Money and Finance 9, 182-192.

D'Agostino, Ralph, Albert Belanger and Ralph D'Agostino Jr., 1990, A suggestion for using powerful and informative tests of normality, The American Statistician 44, 316-321.

Engel, Charles, and Anthony P. Rodriguez, 1989, Tests of international CAPM with time-varying covariances, Journal of Applied Econometrics 4, 119-138.

Engle, Robert, 1982, Autoregressive conditional heteroscedasticity with estimates of the variance of United Kingdom, Econometrica 50, 987- 1007.

French, Kenneth R., and James M. Poterba, 1991, Were Japanese stock prices too high?, Journal of Financial Economics 29, 337-364.

French, Kenneth R., G. William Schwert, and Robert F. Stambaugh, 1987, Expected stock returns and volatility, Journal of Financial Economics 19, 3-30.

Friend, Irwin, and Marshall Blume, 1975, The demand for risky assets, American Economic Review 65, 900-922.

Giovannini, Alberto, and Philippe Jorion, 1989, The time variation of risk and return in the foreign exchange and stock markets, Journal of Finance 44, 307-326.

Glosten, Lawrence, Ravi Jagannathan and David Runkle, 1989, The relationship between the expected value and the volatility of the nominal 
excess return on stocks, unpublished working paper, Northwestern University.

Gultekin, N. Bulent, Mustafa N. Gultekin, and Alessandro Penati, 1989, Capital controls and international market segmentation: The evidence from the Japanese and American stock markets, Journal of Finance 44, 849-869.

Hamao, Yasushi, Ronald Masulis and Victor $\mathrm{Ng}_{\mathrm{g}}, 1990$, Correlations in price changes and volatility across international stock markets, Review of Financial Studies 3, 281-308.

Hansen, Lars and Kenneth Singleton, 1983, Stochastic consumption, risk aversion and the temporal behavior of asset returns, Journal of Political Economy 91, 249-266.

Harvey, Campbell R., 1991, The world price of covariance risk, Journal of Finance 46, 111-157.

Korajczyk, Robert and Claude Viallet, 1989, An empirical investigation of international asset pricing, Review of Financial Studies 2, 553-585.

Lin, Wen-ling, Robert Engle and Takatoshi Ito, 1991, Do bulls and bears move across borders?, unpublished working paper, University of Wisconsin.

McCurdy, Thomas H. and Ieuan G. Morgan, 1991, Tests for a systematic risk component in deviations from uncovered interest rate parity, The Review of Economic Studies 58, 587-602.

McDonald, Jack, 1989, The Mochiai effect: Japanese corporate crossholdings, Journal of Portfolio Management (Fall), 90-94.

Merton, Robert C., 1980, On estimating the expected return on the market: an exploratory investigation, Journal of Financial Economics 8, 323361.

Merton, Robert C., 1973, An intertemporal capital asset pricing model, Econometrica 31, 867-887.

Morgan Stanley, Capital International Perspectives, selected issues.

Muthuswamy, Jayaram, 1990, Non-synchronous trading and the index autocorrelation problem, Ph.D. Dissertation, Graduate School of Business, University of Chicago. 
Nelson, Daniel, 1992, Filtering and forecasting with misspecified ARCH models I: getting the right variance with the wrong model, Journal of Econometrics, forthcoming.

Nelson, Daniel and Dean Foster, 1991a, Estimating conditional variances with misspecified ARCH models: asymptotic theory, unpublished working paper, University of Chicago.

Nelson, Daniel and Dean Foster, 1991b, Filtering and forecasting with misspecified ARCH models II: making the right forecast with the wrong model, unpublished working paper, University of Chicago.

Schwert, William and Paul Seguin, 1990, Heteroskedasticity in stock returns, Journal of Finance 45, 1129-1155.

Sercu, P., 1980, A generalization of the international asset pricing model, Revue de l'Association Francaise de Finance 1, 91-135.

Solnik, Bruno, 1974, Equilibrium in international asset markets under uncertainty, Journal of Economic Theory 8, 500-524.

Stoll, Hans and Robert Whaley, 1990, The dynamics of stock index and stock index futures returns, Journal of Financial and Quantitative Analysis 25, 441-468.

Stulz, René M., 1981, A model of international asset pricing, Journal of Financial Economics 9, 383-406.

Stulz, René M., 1983, Pricing capital assets in an international setting: An introduction, Journal of International Business Studies (Winter), 55-73.

Wheatley, Simon, 1988, Some tests of international equity integration, Journal of Financial Economics 21, 177-212. 


\section{ACKNOWLEDGEMENTS}

The authors thank participants in seminars at Concordia University, Queen's University, Vanderbilt University, University of Western Ontario, Indiana University, University of Chicago, Massachusetts Institute of Technology, University of Minnesota, Ohio State University, Notre Dame University, the NBER Conference on International Asset Pricing in Philadelphia, the Western Economics Association meetings in Seattle, the European Finance Association meetings in Rotterdam, the Johnson Symposium at the University of Wisconsin and the Pacific-Basin Capital Markets Research Conference in Seoul for useful comments. We are grateful to Warren Bailey, Tim Bollerslev, Stephen Brown, George Constantinides, Robert Cumby, Wayne Ferson, Steve Foerster, Pat Hendershott, Robert Hodrick, John Huizinga, Ravi Jagannathan, Bob Korajczyk, Craig Lewis, Andy Lo, Thomas McCurdy, Richard Roll, Paul Seguin, Lemma Senbet, Henri Servaes, Rob Stambaugh, Simon Wheatley and especially the referee, Cam Harvey, and editor, Bill Schwert. James Tompkins and Darrell Lee provided helpful research assistance. K.C. Chan and Andrew Karolyi thank the Dice Center for Financial Economics at Ohio State University for partial funding. 


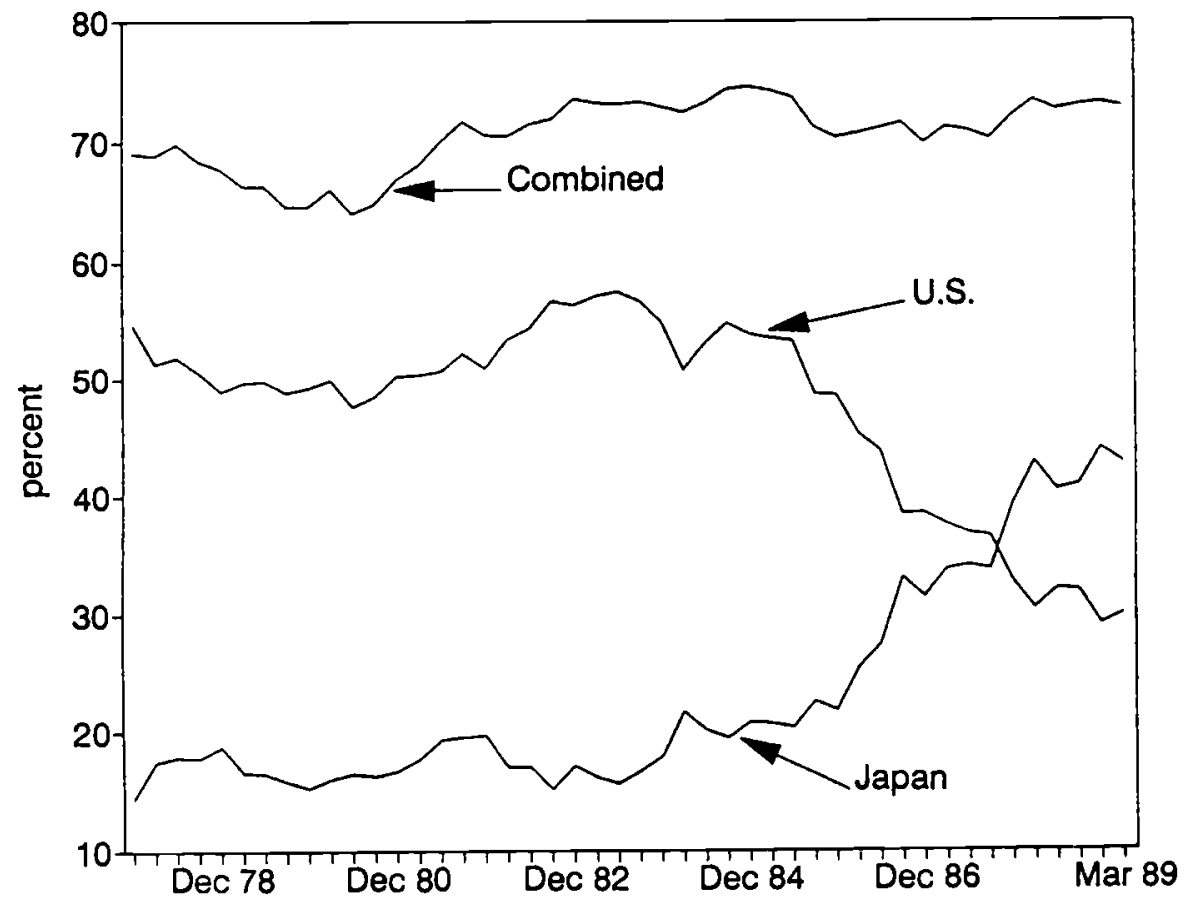

Fig. 1. Market Capitalization of the U.S. and Japanese Equity Markets from 1978 to 1989 as proportion of Total World Equity Market Capitalization. The market values for the U.S. and J apanese stocks are drawn from various quarterly issues of Morgan Stanley's Capital International Perspectives. 


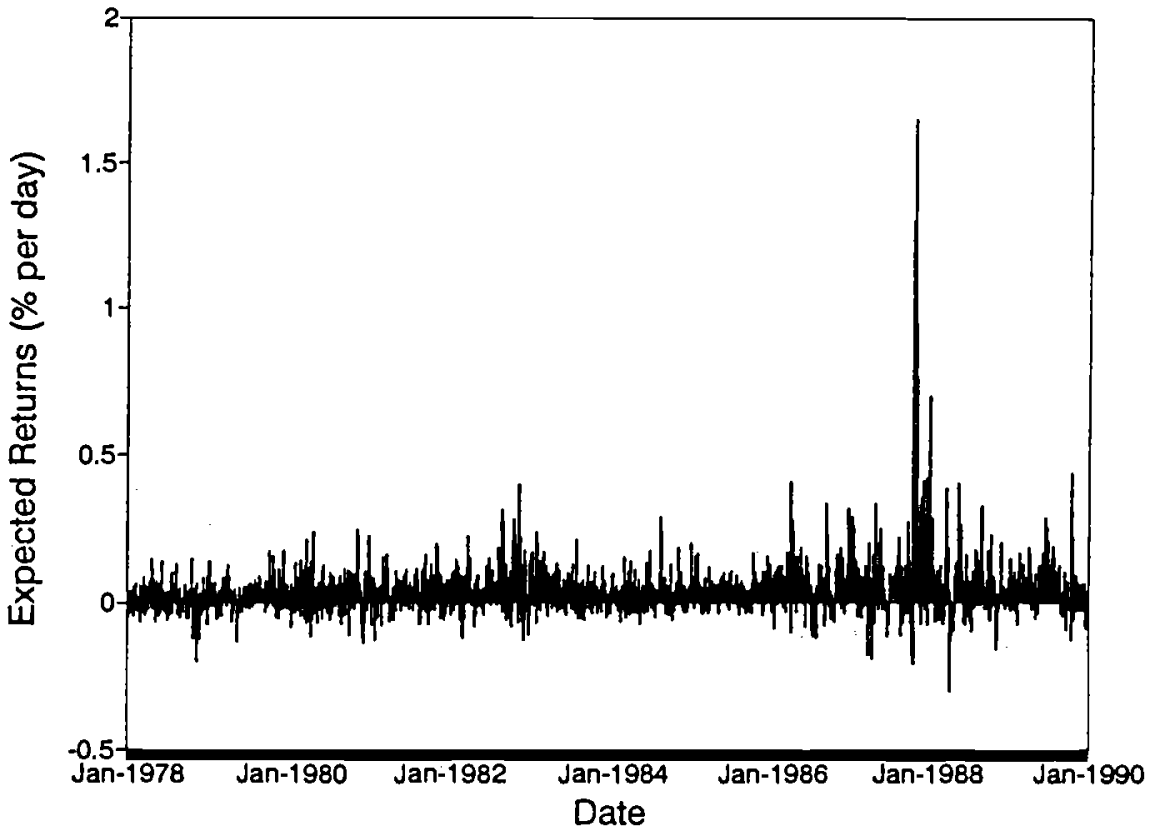

Fig. 2. Conditional Expected Risk Premium on U.S. Equity from 1978 to 1989. The fitted values for the expected risk premium of S\&P 500 index stocks are computed from estimates of the bivariate GARCH model using the dollardenominated Nikkei 225 index returns as the foreign market (Table 2, Panel A). Note that the figure excludes the four days around the October 1987 market crash (October 16, 19, 20 and 21). 


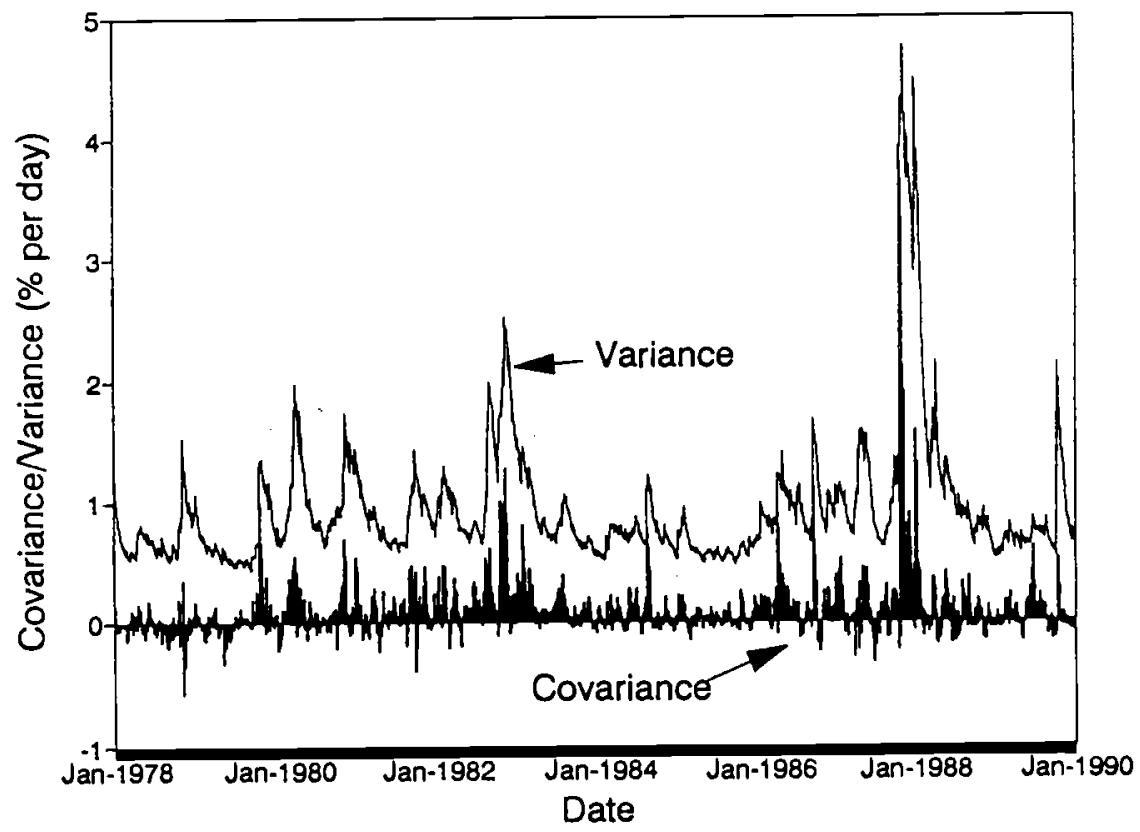

Fig. 3. Conditional Variance and Covariance of the Risk Premium on U.S. Equity from 1978 to 1989 . The fitted values for the conditional variance (line) and covariance (solid bar) of the risk premium of S\&P 500 index stocks are computed from estimates of the bivariate GARCH model using the dollar-denominated Nikkei 225 index returns as the foreign market (Table 2, Panel B). Note that the figure excludes the four days around the October 1987 market crash (October $16,19,20$ and 21 ). 
Table 1

Summary Statiatics for Daily U.S. and Foreign Equity Market Excess Returns (in percent) from January 1978 to December 1989. The U.S. equity index is the Standard and Poor's 500 stock index and the foreign market index is the U.S. dollar- and yendenominated Nikkei 225 index, the Morgan Stanley Japan index (yen-denominated) or the Morgan Stanley EAFE (dollar-denominated) index. All dollar-denominated index returns are computed net of the three-month U.S. Treasury bill yield and the yendenominated index returns are computed net of the three-month Gensalci interest rate. The returns associated with the four days October 16 to October 22 of 1987 are omitted. The Kolmogorov-Smirnoff "D-Statistic" tests null hypothesis of normality with critical values of $0.0256(0.0307), 0.0281(0.0337)$ and $0.0271(0.0325)$ at $5 \%(1 \%)$ significance for 2819,2338 and 2522 degrees of freedom, respectively. The Bera-Jarque "B-Statistic" for normality is based on the excess skewness and kurtosis coefficients and is asymptotically distributed $\chi^{2}$ with two degrees of freedom with critical values at $5 \%$ (1\%) significance of 5.99 (9.21). The tests for deviations from normality for the skewness and kurtosis statistics are based on D'Agostino, Belanger and D'Agostino (1990). Cross-correlations are given between the S\&P 500 index daily excess returns, $r_{t}$, (and squared returns, $r_{t}^{2}$ ) and those of the index shown in the table. "flags coefficients significant at the $1 \%$ level.

Panel A: Distributional Statistics

\begin{tabular}{|l|rrrrr|}
\hline Statistic & S\&P500 & $\begin{array}{r}\text { Nikkei } \\
(\$)\end{array}$ & $\begin{array}{r}\text { Nikkei } \\
\text { (yen) }\end{array}$ & $\begin{array}{r}\text { MSCI } \\
\text { Japan }\end{array}$ & $\begin{array}{r}\text { MSCI } \\
\text { EAFE }\end{array}$ \\
\hline NOBS & 2819 & 2819 & 2819 & 2338 & 2522 \\
Mean & 0.0254 & 0.0693 & 0.0619 & 0.0688 & 0.0495 \\
Std.Dev. & 0.9760 & 1.0648 & 0.7658 & 0.9414 & 0.8917 \\
Skewness & $-0.4409^{*}$ & 0.0535 & $-0.2912^{*}$ & 0.1323 & 0.0327 \\
Kurtosis & $5.6594^{*}$ & $2.2764^{*}$ & $5.8208^{*}$ & $\mathbf{8 . 8 2 6 2}^{*}$ & $3.0575^{*}$ \\
D-Statistic & $0.0525^{*}$ & $0.0469^{*}$ & $0.0759^{*}$ & $0.0858^{*}$ & $0.0357^{*}$ \\
B-Statistic & $72.576^{*}$ & $11.489^{*}$ & $75.706^{*}$ & $157.09^{*}$ & $19.570^{*}$ \\
& & & & & \\
\hline
\end{tabular}

Panel B: Autocorrelations of Daily Excess Returns

\begin{tabular}{|l|rrrrr|}
\hline Statistic & S\&P500 & $\begin{array}{r}\text { Nikkei } \\
(\$)\end{array}$ & $\begin{array}{r}\text { Nikkei } \\
\text { (yen) }\end{array}$ & $\begin{array}{r}\text { MSCI } \\
\text { Japan }\end{array}$ & $\begin{array}{r}\text { MSCI } \\
\text { EAFE }\end{array}$ \\
\hline Series: $r_{t}$ & & & & & \\
$\rho_{1}$ & $.0552^{*}$ & $.0975^{*}$ & $.0934^{*}$ & $.1229^{*}$ & $.1059^{*}$ \\
$\rho_{2}$ & .0077 & .0027 & $-.0604^{*}$ & $-.0646^{*}$ & .0258 \\
$\rho_{3}$ & -.0234 & .0246 & -.0024 & .0051 & .0191 \\
$\rho_{4}$ & -.0042 & .0345 & .0134 & .0167 & .0300 \\
$\rho_{3}$ & -.0086 & -.0295 & $-.0507^{*}$ & $-.0695^{*}$ & .0079 \\
$\rho_{6}$ & -.0047 & -.0004 & -.0379 & -.0296 & -.0100 \\
& & & & & \\
\hline Series: $r_{t}^{2}$ & & & & & \\
$\rho_{1}$ & $.0675^{*}$ & $.1492^{*}$ & $.2617^{*}$ & $.1156^{*}$ & $.1493^{*}$ \\
$\rho_{2}$ & $.0792^{*}$ & $.1025^{*}$ & $.1826^{*}$ & $.2121^{*}$ & $.0619^{*}$ \\
$\rho_{3}$ & $.1641^{*}$ & $.0600^{*}$ & $.1853^{*}$ & $.2134^{*}$ & $.1009^{*}$ \\
$\rho_{4}$ & $.1227^{*}$ & $.0451^{*}$ & $.1003^{*}$ & .0466 & $.1123^{*}$ \\
$\rho_{5}$ & $.0824^{*}$ & $.0749^{*}$ & $.1211^{*}$ & $.1413^{*}$ & $.0866^{*}$ \\
$\rho_{6}$ & $.1463^{*}$ & .0206 & $.0966^{*}$ & $.0711^{*}$ & .0219 \\
& & & & & \\
\hline
\end{tabular}


Table 1 (continued)

Panel C: Croas-correlations of Daily S\&P 500 and Foreign Market Excess Returns

\begin{tabular}{|c|c|c|c|c|c|c|c|c|}
\hline \multirow[b]{2}{*}{ Lag } & \multicolumn{2}{|c|}{ Nikckei (\$) } & \multicolumn{2}{|c|}{ Nikkei (yen) } & \multicolumn{2}{|c|}{ MSCI Japan } & \multicolumn{2}{|c|}{ MSCI EAFE } \\
\hline & $r_{t}$ & $r_{t}^{2}$ & $T_{t}$ & $r_{t}^{2}$ & $T_{t}$ & $r_{1}^{2}$ & $r_{t}$ & $r_{f}^{2}$ \\
\hline-6 & -0.0167 & 0.0377 & $-0.0394^{*}$ & $0.0689^{*}$ & -0.0263 & 0.0363 & 0.0034 & $0.0404^{*}$ \\
\hline-5 & 0.0188 & $0.0567^{*}$ & 0.0177 & $0.0786^{*}$ & 0.0255 & $0.0418^{*}$ & 0.0061 & $0.0630^{*}$ \\
\hline-4 & -0.0051 & $0.0487^{*}$ & -0.0153 & $0.0929^{*}$ & -0.0319 & $0.0783^{*}$ & -0.0022 & $0.1539^{*}$ \\
\hline-3 & 0.0029 & $0.0609^{*}$ & -0.0144 & $0.1268^{*}$ & -0.0171 & $0.0782^{*}$ & 0.0390 & $0.0746^{*}$ \\
\hline-2 & $0.0571^{*}$ & $0.0770^{*}$ & $0.0689^{* \prime}$ & $0.1451^{*}$ & $0.1004^{*}$ & $0.1061^{*}$ & $0.0456^{*}$ & $0.0545^{*}$ \\
\hline-1 & $0.1916^{*}$ & $0.1516^{*}$ & $0.2707^{*}$ & $0.2139^{\prime \prime}$ & $0.2531^{*}$ & $0.1642^{*}$ & $0.3305^{*}$ & $0.1854^{*}$ \\
\hline 0 & $0.0838^{*}$ & $0.1522 *$ & $0.1201^{*}$ & $0.2003^{*}$ & $0.1095^{*}$ & $0.1269^{*}$ & $0.1629^{*}$ & $0.2190^{*}$ \\
\hline 1 & 0.0137 & $0.1021^{*}$ & -0.0033 & $0.2194^{*}$ & -0.0041 & $0.1999^{*}$ & 0.0062 & $0.0954^{*}$ \\
\hline 2 & 0.0015 & $0.0754^{*}$ & -0.0164 & $0.1906^{*}$ & -0.0342 & $0.1806^{*}$ & 0.0099 & $0.0504^{*}$ \\
\hline 3 & $0.0536^{*}$ & 0.0356 & $0.0411^{*}$ & $0.0747^{*}$ & $0.0422 *$ & $0.1556^{*}$ & 0.0195 & $0.0749^{*}$ \\
\hline 4 & -0.0356 & $0.0675^{*}$ & $-0.0471^{*}$ & $0.1129^{*}$ & -0.0281 & $0.0889^{*}$ & -0.0353 & $0.0555^{*}$ \\
\hline 5 & -0.0206 & $0.0444^{*}$ & -0.0284 & $0.1274^{*}$ & $-0.0483^{*}$ & $0.1036^{*}$ & -0.0288 & 0.0202 \\
\hline 6 & -0.0044 & $0.0441^{*}$ & -0.0198 & $0.0647^{*}$ & -0.0044 & 0.0336 & -0.0001 & $0.0464 *$ \\
\hline
\end{tabular}




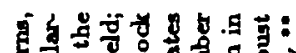

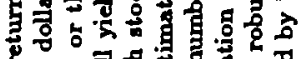

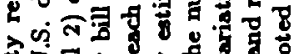

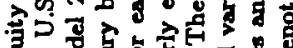
8 .

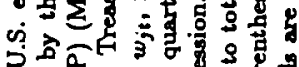

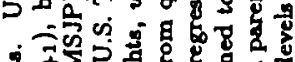

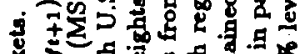

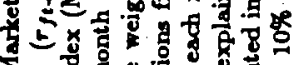
र.

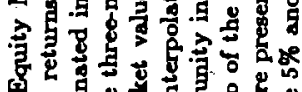
舟

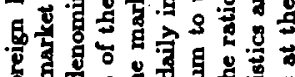
s.

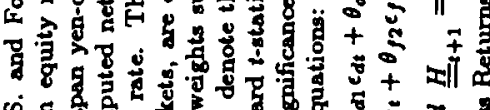
S.

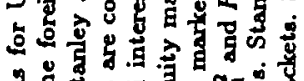

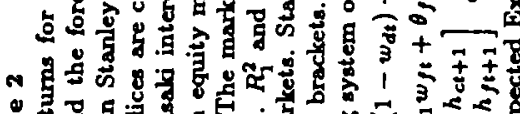

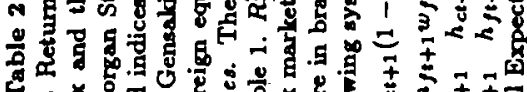

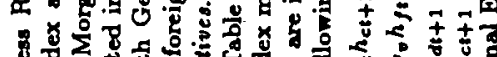

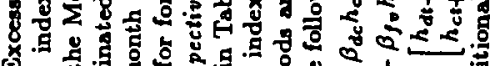

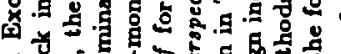

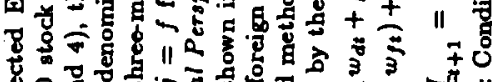

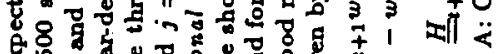

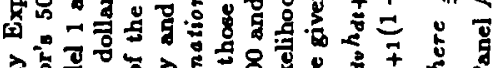

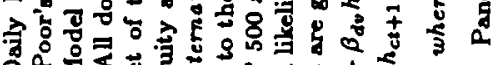
की 万人

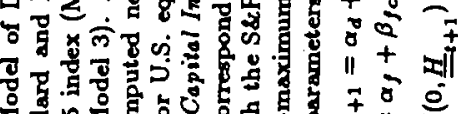

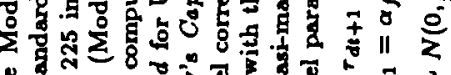

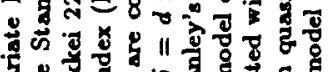
은

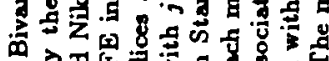
के

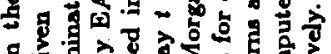
6.

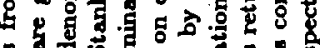
8 क के

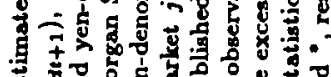

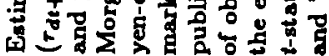

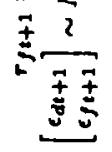

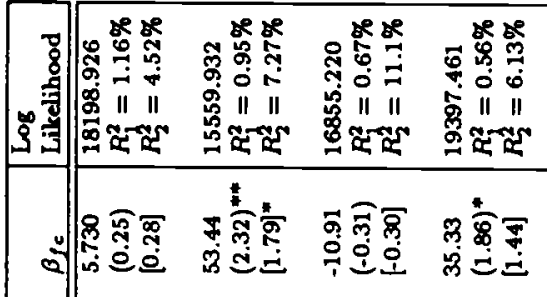

용 a

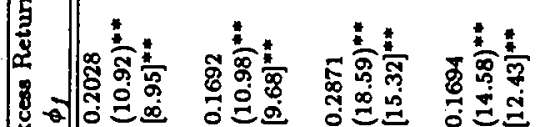
(4)

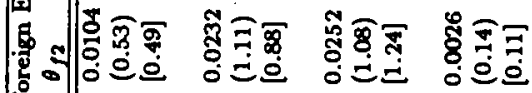

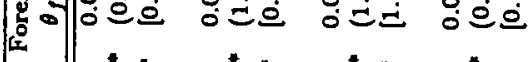

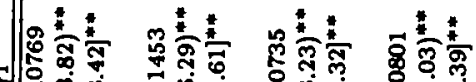

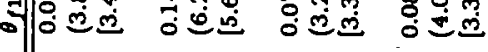
商哥 -

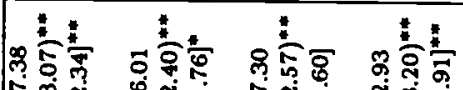

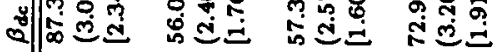

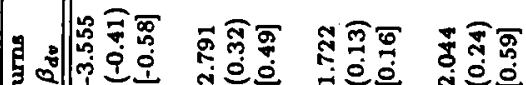
70

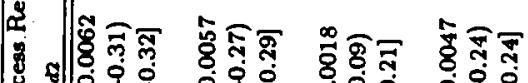

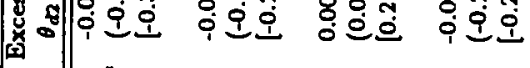

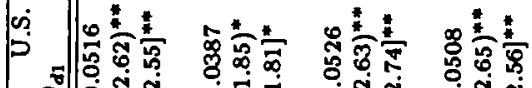




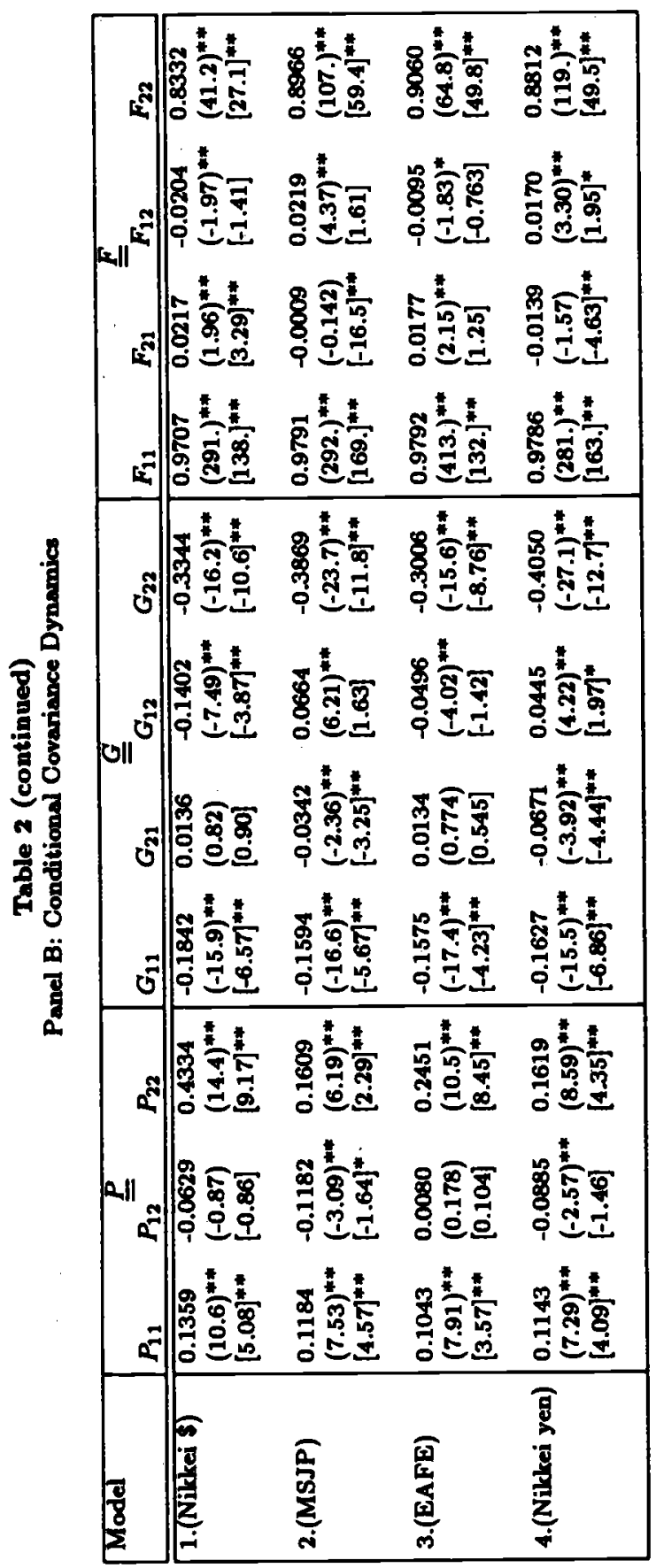


Table 9

Tests of the International CAPM and Alternative Specifications using the Bivariate Model of Daily Expected Excess Returns for U.S. and Foreign Equity Markets. U.S. equity returns are given by the Standard and Poor's 500 stock index and the foreign equity market returns, by the U.S. dollar- and yen-denominated Nikkei 225 index (Model 1 and 4), the Morgan Stanley Japan index (MSJP) (Model 2) or the Morgan Stanley EAFE index (Model 3). The restrictions associated with the ICAPM model are $\beta_{d v}=\beta_{d c}=\beta_{f v}=\beta_{f c}$, for "Alternative 1 - Segmented" that assumes that the prices of risk in the U.S and foreign market differ, $\beta_{d v}=\beta_{d c}$ and $\beta_{f v}=\beta_{f c}$, and for "Alternative 2 - Hedging" that assumes a two factor model with U.S and foreign market risk as the respective losdings, $\beta_{d v}=\beta_{f c}$ and $\beta_{f v}=\beta_{d c}$. Only the coefficient eatimates for the conditional variance and covariance terms in the S\&P 500 and foreign market excess returns equations are reported with associated robust t-statistics computed with quasi-maximum likelihood methods in brackets and $x^{2}$ values of the likelihood ratio test of the restrictions. Significance at the $5 \%$ and $10 \%$ levels are denoted by ** and *.

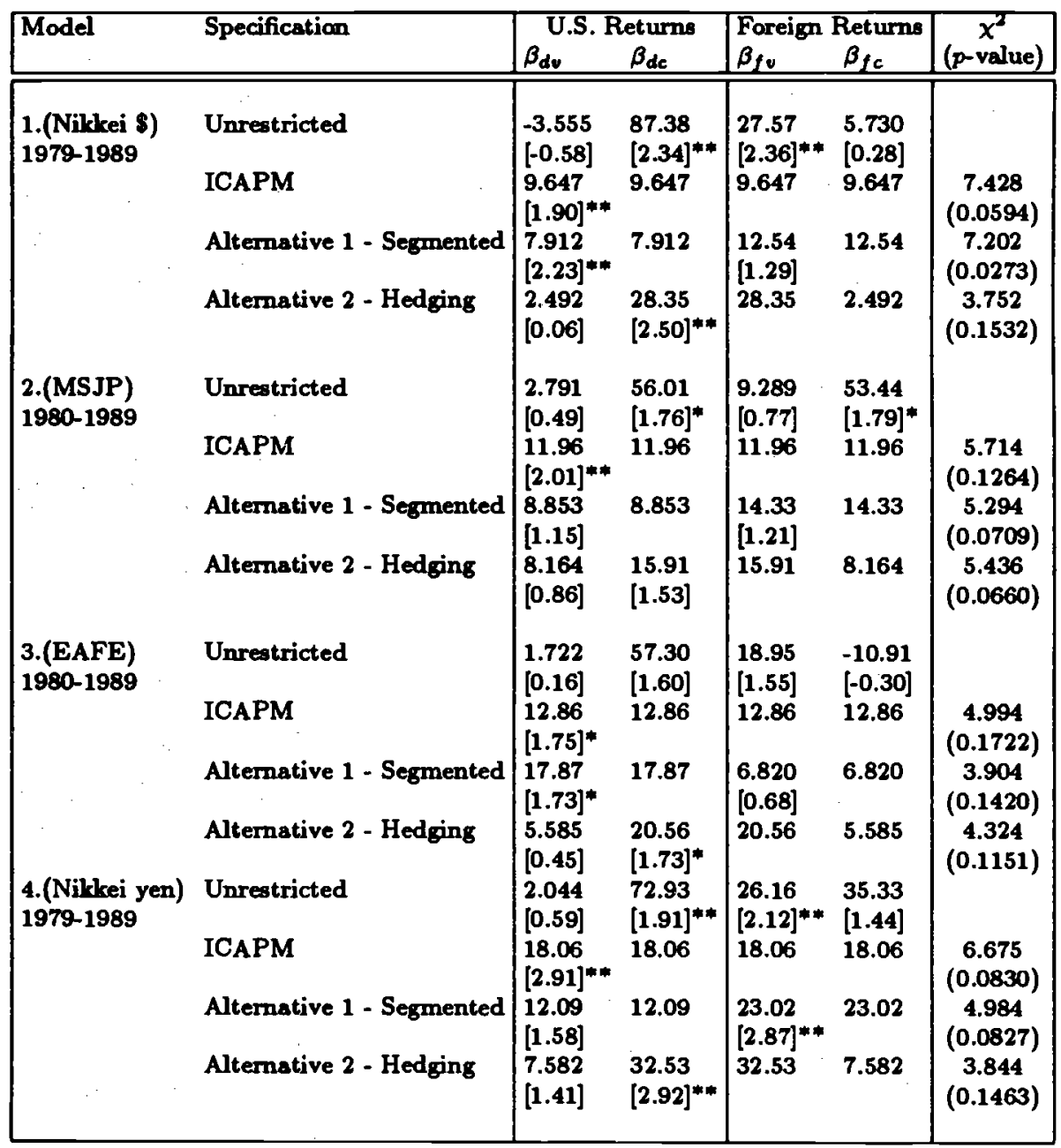




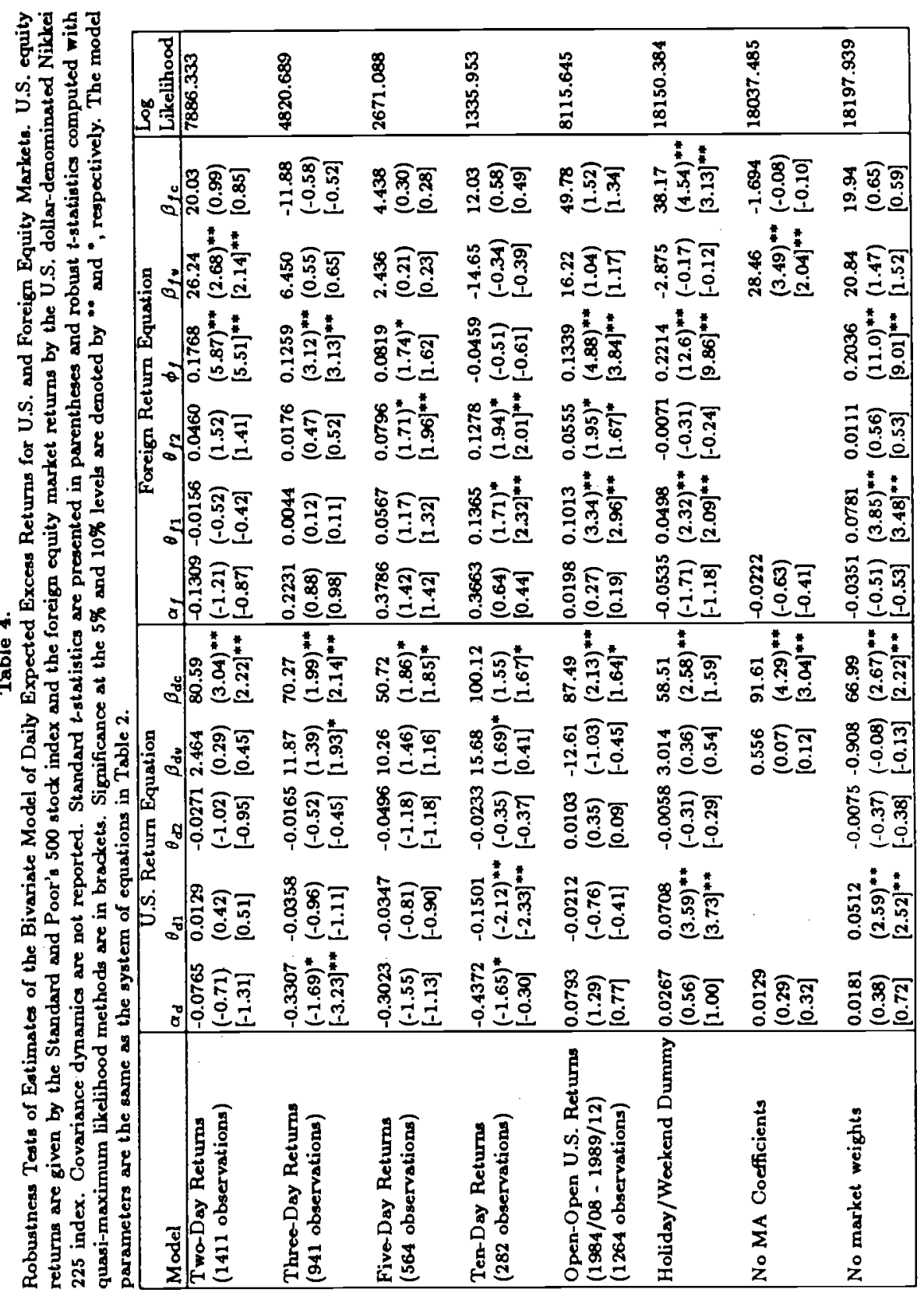


Table $\mathbf{5}$

Residual Diagnostics for Bivariate GARCH Models for Daily U.S. and Foreign Equity Market Excess Returns from January 1978 to December 1989. The corresponding model eatimates are from Tables 2. The U.S. equity index is the Standard and Poor's 500 stock index and the foreign market index is the U.S. dollar- or yen-denominated Nikkei 225 index, the Morgan Stanley Japan index or the Morgan Stanley EAFE index. The KolmogorovSmirnof "D- statistic" tests null hypothesis of normality with critical values of 0.0256 $(0.0307), 0.0281(0.0337)$ and $0.0271(0.0325)$ at $5 \%(1 \%)$ significance for 2819,2338 and 2522 degrees of freedom, respectively. The Bera-Jarque "B- statistic" for normality is based on the excess skewness and kurtosis coefficients and is asymptotically distributed $\chi^{2}$ with two degrees of freedom with critical values at $5 \%(1 \%)$ significance of 5.99 (9.21). The tests for deviations from normality for the skewness and kurtosis statistics are based on D'Agostino, Belanger and D'Agostino (1990). $\rho_{j}$ denotes the autocorrelation coefficients of order $j$ for both the raw and squared standardized residuals. Cross-correlations are given between the residuals from the S\&P 500 index daily excess returns, $\hat{c}_{t}$, (and squared returns, $\hat{\epsilon}_{t}^{2}$ ) and those of the index shown in the table. *lags coefficients for which tests indicate significance at the $1 \%$ level.

Panel A: Bivariate Model Standardized Residuals

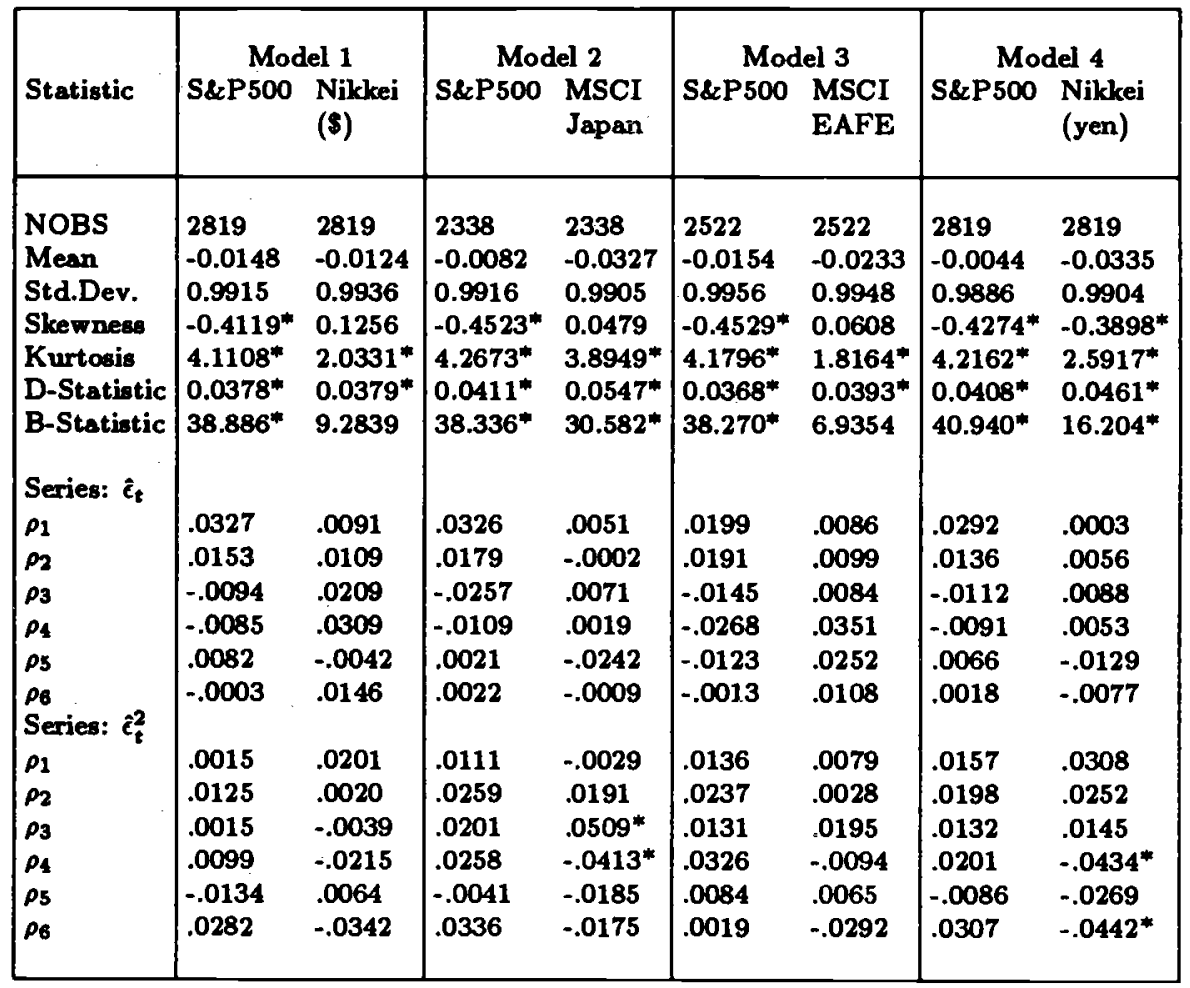


Table 5 (continued)

Panel B: Crose-correlatione of Standardized Residuals of Bivariate Modele of S\&P 500 and Foreign Market Returns

\begin{tabular}{|c|c|c|c|c|c|c|c|c|}
\hline \multirow{2}{*}{ Lag } & \multicolumn{2}{|c|}{$\begin{array}{c}\text { Model } 1 \\
\text { Nikkei (8) }\end{array}$} & \multicolumn{2}{|c|}{$\begin{array}{cc}\text { Model } 2 \\
\text { MSCI Japan } \\
\hat{\epsilon}_{t} \quad \hat{\epsilon}_{t}^{2}\end{array}$} & \multicolumn{2}{|c|}{$\begin{array}{c}\text { Model 3 } \\
\text { MSCI EAFE }\end{array}$} & \multicolumn{2}{|c|}{$\begin{array}{c}\text { Model } 4 \\
\text { Nilkkei (yen) }\end{array}$} \\
\hline & -0.0009 & 0.0018 & -0.0018 & -0.0085 & 0.0209 & -0.0147 & -0.0123 & 0.0005 \\
\hline-5 & 0.0254 & -0.0091 & $0.0421^{*}$ & 0.0088 & 0.0169 & 0.0053 & 0.0227 & -0.0084 \\
\hline-4 & -0.0083 & -0.0139 & -0.0144 & -0.0116 & 0.0200 & 0.0186 & -0.0073 & -0.0089 \\
\hline-3 & -0.0013 & 0.0005 & -0.0102 & 0.0067 & 0.0223 & 0.0287 & -0.0078 & 0.0257 \\
\hline-2 & $0.0457^{\star}$ & 0.0136 & $0.0879^{*}$ & 0.0370 & 0.0356 & 0.0199 & $0.0571^{*}$ & $0.0449^{*}$ \\
\hline-1 & -0.0003 & 0.0166 & 0.0366 & $0.0478^{*}$ & 0.0103 & $0.0523^{\star}$ & 0.0263 & $0.0410^{*}$ \\
\hline 0 & $0.0579^{*}$ & $0.0959^{*}$ & $0.0762^{*}$ & 0.0379 & $0.1349^{*}$ & $0.1315^{*}$ & $0.0747^{*}$ & $0.0686^{*}$ \\
\hline 1 & 0.0072 & $0.0559^{*}$ & 0.0099 & $0.1350^{*}$ & -0.0047 & 0.0346 & 0.0035 & $0.0687^{*}$ \\
\hline 2 & 0.0086 & 0.0183 & 0.0060 & 0.0266 & 0.0285 & 0.0223 & 0.0157 & 0.0298 \\
\hline 3 & $0.0549^{*}$ & -0.0054 & 0.0371 & -0.0160 & 0.0318 & 0.0281 & $0.0420^{\star}$ & -0.0195 \\
\hline 4 & -0.0174 & 0.0323 & 0.0052 & 0.0125 & -0.0278 & -0.0065 & -0.0155 & 0.0158 \\
\hline 5 & -0.0143 & 0.0274 & -0.0261 & $0.0611^{*}$ & -0.0008 & 0.0078 & -0.0205 & 0.0255 \\
\hline 6 & -0.0109 & -0.0082 & -0.0093 & 0.0151 & 0.0151 & 0.0172 & -0.0264 & 0.0116 \\
\hline
\end{tabular}

